tive. Notes of flower colour and season of flowering would enhance the usefulness of the Flora to the layman.

It is very easy for those of us who have been brought up in regions that are well known botanically to pick flaws in a pioneer work covering an area that is little known. We should remember, when we are tempted to criticize, the very great debt we owe to men like Prof. Moss (need we mention Ridley, Asa Gray, or J. D. Hooker), who, in their retirement, have not been content to rest, but have, instead, given us basic works to build on. Their errors may or may not be glaring. They, not we, have done the work.

Gordon P. DEWolf, JUN.

\section{THE CHEMISTRY OF AIR POLLUTION}

The Chemical Analysis of Air Pollutants

By Dr. Morris B. Jacobs. (Chemical Analysis : a Series of Monographs on Analytical Chemistry and Its Applications, Vol. 10.) Pp. xviii +430. (New York: Interscience Publishers, Inc.; London : Interscience Publishers, Ltd., 1960.) $102 s$.

NE need not be a chemist to appreciate the evergrowing menace of air pollution in urban com. munities. Too often the discomforts and dangers of the winter 'smog' descend on a choking populace, apparently powerless to alleviate the distress caused by its own machinations. This is pollution at its obvious worst, but there are many other forms of pollution which though less conspicuous are no less hazardous and indeed, in the case of radioactive contamination, can have such far-reaching effects that the entire populace of an affected area must be evacuated.

In order to control air pollution, it is first necessary to measure it, and this involves the determination of the nature and amount of the contaminating materials. In this book, Dr. Jacobs, who is a wellknown consultant in this field, sets out his systematic approach to the many chemical and physical problems involved in analysis of gaseous and particulate contaminants in air.

Chapter 1 contains a general account of sampling and the available means of taking samples for analysis. Chapter 2 is devoted to the measurement of volume, quantity, and velocity of gases. Chapter 3 considers sootfall and dustfall, and the analysis of soots and dusts by a number of standard methods. Chapter 4 deals with the evaluation of atmospheric dust, particularly the particle sizes involved. Chapter 5 , on suspended particulate matter, gives procedures for the chemical analysis of organic and inorganic constituents. Chapters 6 and 7 deal respectively with smoke density and smoke shade, and the sampling and analysis of industrial stack-smoke. Chapters 8 and 9 cover the chemical analysis of sulphur and halogen-containing air pollutants, Chapter 10, that of nitrogenous compounds and ozone, Chapter 11, oxides of carbon, cyanide, and phosgene, and Chapter 12, general organic compounds. In Chapter 12 these materials are arranged according to their functional groupings. Chapter 13 covers the determination of radioactivity and the detection and determination of hazardous isotopes such as strontium-90. The analysis of incinerator-flue gases and motorvehicle exhaust gases is dealt with in Chapters 14 and
15. Chapter 16 deals with the interesting subject of 'odour' analysis, which involves the determination of the amount of a (generally) malodorous material in the atmosphere. The final chapter (18) describes instruments used to monitor particular types of air contaminants. An appendix contains a number of useful tables and data pertinent to the information given in the text.

The wealth of information given in this book and the concise and systematic way in which it is presented must make it an obvious choice for all who are interested in the control of air pollution. Its use is not restricted in any way by its contents which are directed primarily to the analyst, but are of interest to a much wider section of the community, such as engineers, factory inspectors, public health and sanitation officers. Much of the analytical chemistry can be adapted for courses in colleges and universities, and the inclusion of many simple and inexpensive methods is of great value not only to teaching institutes, but also to the many communities and industrial organizations which do not have the funds necessary to set up the more elaborate methods and instrumental techniques.

For the analytical chemist, this book provides an admirable addition to the literature on applied analysis. It maintains the high standard of its predecessors in the Interscience series of Monographs on Analytical Chemistry and its Applications, and it must undoubtedly become a standard work on the subject of air pollution.

W. I. STEPHEN

\section{VEGETABLE PATHOLOGY}

\section{Vegetable Diseases and Their Control}

By Prof. Charles Chupp and Prof. Arden F. Sherf. Pp. v +693 . (New York: The Ronald Press Company, 1960.) 12 dollars.

A

LTHOUGH directed primarily at the American reader this publication should prove of interest to those in Great Britain and elsewhere.

After preliminary sections on seedling diseases and those affecting a range of host plants, there are sixteen chapters esch dealing with the diseases of a group of vegetables. Potatoes are not included. The book concludes with chapters on minor element deficiencies, nematodes and soil sterilization. A valuable feature is the mention of varieties that show resistance to the various diseases.

As indicated in the preface to the volume, an attempt has been made to write in as nearly a nontechnical manner as possible so that the book may be of use to the amateur as well as to the commercial grower. Considerable success has been achieved in this respect and the narrative style is very readable, a feature which is assisted by the excellent clear type. The sections abound in practical recommendations for control and obviously contain the fruits of many years experience in this field.

The book is also intended to serve as a text for students, research specialists and advisers, but its value in this respect is less apparent. There are few sub-headings within the sections on each disease; with a few minor exceptions there are no drawings or photographs of the causal organisms, and little or no mention is made in the text of the references quoted at the end of each section. These therefore 